Original Research Paper

\title{
Building Information Modeling for Indoor Environmental Performance Analysis
}

\author{
Yaik-Wah Lim \\ Department of Architecture, Faculty of Built Environment, Universiti Teknologi Malaysia, Malaysia
}

Article history

Received: 04-09-2014

Revised: 09-03-2015

Accepted: 25-03-2015

\begin{abstract}
There are increasing numbers of Building Information Modeling (BIM) software available nowadays which change the working methods in Architecture, Engineering and Construction (AEC) industry. From the stages of building design development to postoccupancy management, BIM plays an essential role in collaboration among multi-discipline professions, time and cost saving, fabrication and construction as well as facilities management. With the arising concern for sustainability in built environment, BIM software is also developed to simulate building indoor environmental performances. The aim of this study is to review the latest development of BIM-based indoor environmental performance analysis for sustainable building design. Various state-of-the-art BIM-based sustainability tools which are commonly employed by AEC industry are reviewed and compared in relation with design parameters and performance outputs. The advantages and disadvantages of the software are analyzed. The comparison allows proper selection of software which determines the effectiveness and reliability of simulation process and outputs. The prospects of BIM development and its applications for indoor environmental studies are also discussed. The review concludes that BIM-based sustainability simulation during early or pre-design stage is very crucial to develop sustainable building design. Further research on the framework and guidelines for BIM-based sustainability analyses and design process shall be conducted.
\end{abstract}

Keywords: Building Performance Simulation, Daylighting, Solar Radiation, CFD, Sustainability

\section{Introduction}

Sustainability has been a major issue in Architecture, Engineering and Construction (AEC) industry since the energy crisis and arising concerns for the climate change. Many studies had concluded that the best opportunities for improving building environmental performances occur in the early design or pre-construction stages (Lim, 2012; Azhar and Brown, 2009). Nevertheless, surveys had found that in the conventional AEC practice, architects prefer to analyze the building performances in the later stages, usually by consulting an engineer (Pedrini and Hyde, 2001; Schlueter and Thesseling, 2009). There are many factors for this situation including the misunderstanding of building performance, the absence of suitable methods for architects, detailed modeling and input data are required in order to run an accurate simulation.

Due to the decrease of hardware cost and the increase of computer speed and storage since 1970's, increasing numbers of computer building modeling tools are made available (Loutzenhiser et al., 2007; Xia et al., 2008). With the development of Building Information Modeling (BIM) technology, complicated building modeling can be digitally constructed with precise geometry and accurate information to support the project construction, fabrication, analysis and procurement activities. Many researchers had stated the benefits of BIM in Architecture, Engineering and Construction (AEC) industry such as accurate building information data environment, more effective design process, increased accuracy in project cost estimation, reduction in project time, saving contract 
value through clash detections (Gu and London, 2010; Sanguinrtti et al., 2012; Barlish and Sullivan, 2012; Bryde et al., 2013). BIM is believed to transform the architectural design process and the ways AEC industry operates.

BIM also allows parametric design and building performance analysis. Nowadays, BIM software integrates thermal, daylighting, energy and Computational Fluid Dynamic (CFD) performances simulations (Azhar and Brown, 2009). These simulation tools are able to analyze and improve building environmental performances throughout the design development stages. Thus the benefits of BIM for green building design had been investigated widely by researchers recently. For instance, the data of BIM model can be utilized for green certification or sustainable building design decision making (Azhar et al., 2011; Kim et al., 2013; Bank et al., 2010).

The development of BIM-based sustainability tools which integrate the design model and the simulation can analyze multi-disciplinary information in a single model which improves the analysis and eliminates errors of data handling (Azhar et al., 2011). The intelligent information created by the BIM model can conduct whole-building energy analysis, simulate performance and visualize appearance (McGHC, 2010). This provides building designers with direct feedback to improve building performance over the lifecycle of the building. The current paper will discuss some of the state-of-the-art BIM-based sustainability tools and their applications for indoor environmental performance studies. Besides, the prospect of BIM-based sustainability simulation is also presented.

\section{Bim-Based Sustainability Tools}

There are various BIM tools available in the market. According to (Azhar et al., 2008), the top three authoring tools are Autodesk $\AA$ Revit ${ }^{\mathrm{TM}}$, Graphisoft ${ }^{\circledR} \quad$ Constructor ${ }^{\mathrm{TM}}$ and Bentley ${ }^{\circledR}$ Architecture $^{\mathrm{TM}}$. The information consisted in a BIM model can be directly extracted for building performance analysis simulation in BIM-based sustainability tools. Appropriate selection of BIM-based sustainability tool is very important to optimize the modeling and simulation process as well as output performances. It is essential for architects and engineers to know the project stage or task to perform when applying BIMbased simulation. Besides, they have to be aware of the available input data and required simulation output. They need to acquire certain expertise based on their professions in order to employ these BIMbased simulation tools (Lim et al., 2008).

In this study, three BIM-based analysis and simulation tools are selected for comparison: (1)
Autodesk Ecotect Analysis, (2) Integrated Environment Solution <Virtual Environment $>$ (IES $<\mathrm{VE}>$ ) and (3) Design Builder. They are commonly used by architects and engineers for building performance simulation. Not all kinds of design or performance variables are available in the simulation tools. Each of them has their limitations. Hence, it is essential to select suitable tools that are able to provide the required design variables (independent) and performance variable (dependent). Sometimes combination of different tools is required in order to perform better simulation results. Table 1 shows the summary of the design and performance variables for the selected BIM-based simulation tools.

Autodesk Ecotect Analysis is suitable for architect or designer to simulate the building performance in early design stage or conceptual massing. This is because it provides user-friendly interface and graphical result outputs which are suitable for visual presentation. It also allows for self-generated optimum shading design which assists architect or designer to determine the shading strategies during the design development stage. However, the accuracy of this tool is questionable. According to Ibarra and Reinhart (2009), Autodesk Ecotect Analysis was compared with Radiance-based simulation results and concluded that Autodesk Ecotect Analysis which uses split flux method is not a reliable tool for daylighting simulation. However, this tool allows export to other simulation tools such as Radiance and Daysim for more accurate daylighting simulation; EnergyPlus, DOE-2 and eQUEST for more detailed energy and thermal simulations.

IES $<$ VE $>$ integrates several simulation engines to allow more complete simulations including CFD and energy consumption. Thus, one single building modeling can be used for different simulations. This tool employs Apache simulation engine for thermal and energy simulations. Radiance, which is developed by Greg Ward at Lawrence Berkeley National Laboratories and widely recognized by the lighting professionals, is integrated for daylighting simulation (Reinhart and Fitz, 2006; Lim et al., 2010; 2012). Most of the performances in Radiance are available in IES $<\mathrm{VE}>$ such as simulating illuminance, luminance, daylight factor and glare index under various CIE sky conditions. MacroFlo and MicroFlo were employed for airflow and CFD simulations. Although CFD is available in IES $<\mathrm{VE}>$, its application is limited to simple geometry and less detailed modeling. The new developments of IES VE-Ware and IES VE-toolkits provide connectivity to BIM software such as Autodesk Revit Architecture and Revit MEP. However, training is needed to master IES $<\mathrm{VE}>$ due to the complicated data input and user-interface.

Design Builder is another integrated simulation tool which allows one single modeling for various simulations. 
Table 1. Summary of design and environmental performances variables of BIM-based simulation tools

\begin{tabular}{|c|c|c|c|c|c|c|c|c|c|c|c|c|c|c|c|c|c|c|c|c|c|c|c|c|c|}
\hline \multirow[b]{3}{*}{$\begin{array}{l}\text { BIM-based } \\
\text { simulation tools }\end{array}$} & \multirow[b]{3}{*}{$\begin{array}{l}\text { Weather } \\
\text { date file }\end{array}$} & \multirow[b]{3}{*}{$\begin{array}{l}\text { Graphical } \\
\text { interface }\end{array}$} & \multicolumn{12}{|c|}{ Modeling design variable } & \multicolumn{11}{|c|}{ Performance variable } \\
\hline & & & \multicolumn{3}{|c|}{ External shading } & \multicolumn{3}{|c|}{ Internal shading } & \multicolumn{6}{|c|}{ Building geometry } & \multicolumn{4}{|l|}{ Thermal } & \multicolumn{4}{|l|}{ Visual } & \multicolumn{3}{|l|}{ Other } \\
\hline & & & $\begin{array}{l}1 \text { Horiz } \\
\text {-ontal } \\
\end{array}$ & Vertical & $\begin{array}{l}\text { Egg } \\
1 \text {-crate }\end{array}$ & Louvers & s Blinds & $\begin{array}{l}\text { Glazing } \\
\text { type }\end{array}$ & Depth & Width & Angle & $\begin{array}{l}\text { Window } \\
\text { size }\end{array}$ & Color & $\begin{array}{l}\text { Orient } \\
\text {-ation }\end{array}$ & $\begin{array}{l}\text { Solar } \\
\text { radiation }\end{array}$ & $\begin{array}{c}\text { Solar } \\
\text { n transmit }\end{array}$ & $\begin{array}{l}\text { Tempe } \\
\text {-rature }\end{array}$ & CFD & $\begin{array}{l}\text { Illumi } \\
\text {-nance }\end{array}$ & $\begin{array}{l}\text { Lumi } \\
\text {-nance }\end{array}$ & $\begin{array}{l}\text { Daylight } \\
\text { factor }\end{array}$ & Glare & View & Energy & Acoustic \\
\hline $\begin{array}{l}\text { Ecotect analysis } \\
\text { IES }<\text { VE }>\end{array}$ & $\because$ & $:$ & : & $\because$ & $\dot{:}$ & $:$ & $\dot{:}$ & $:$ & & & $:$ & 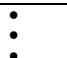 & $:$ & $\bullet$ & $:$ & : & $\dot{:}$ & $:$ & & $\bullet$ & : & - & $\bullet$ & & $\bullet$ \\
\hline
\end{tabular}

One of the advantages of this tool is employing Energy Plus, which is a widely accepted and reliable simulation engine, for thermal and energy simulations (Loutzenhiser et al., 2007; Crawley et al., 2001). This simulation engine is developed by the US Department of Energy through building on development experience with two earlier programs: DOE-2 and BLAST. Besides, Design Builder also uses Radiance as daylighting simulation engine but with limited performances available. Luminance and glare analysis are not available in Design Builder, thus limited the usage for daylighting quality study. Design Builder CFD gives more detailed analysis in comparison with IES $<\mathrm{VE}>$. It allows both external and internal airflow analysis to be simulated together.

BIM-based sustainability simulation is the most time and cost saving method that allows testing on variety of design configurations. It allows study of building performance from the design development stage until post occupancy evaluation. A BIM model can be employed for various simulations. It does not require cost for physical model or building construction. Apart from that, it is user-friendly especially to architects because it does not require advanced mathematical calculations. Nevertheless, proper selection of the tools determines the effectiveness and reliability of the performance simulation. Apart from that, understanding of the process of applying the tools is important to assure the successfulness of the project.

\section{Application}

A BIM model is defined as a data-rich, objectoriented, intelligent and parametric digital representation of the facility. Information can be generated from views and data appropriate to various users' needs to make decisions and to improve the process of delivering the facility (AGCA, 2005). Another definition of BIM is "an intelligent $3 \mathrm{D}$ virtual building model that can be constructed digitally by containing all aspects of building information-into an intelligent format that can be used to develop optimized building solutions with reduced risk and increase value before committing to a design proposal" (Woo et al., 2010). Thus, the information or data of a BIM model can be exported to green building Extensible Markup Language (gbXML) file for performance analysis in various sustainability simulation tools. Figure 1 illustrates the workflow of the application of BIMbased sustainability tools.

The information that is exported for simulation includes building construction materials, building type, space volume, site location and building orientation, thermal properties. Therefore, it is important to construct an accurate model with proper zoning. For instance, in Autodesk Revit, the zones or spaces are identified as 'rooms'. The volume and thermal properties of a 'room' will be exported for simulation. When the gbXML file is imported into an integrated BIM-based simulation tool, various indoor environmental performances can be simulated including thermal (heat gain and comfort), visual (daylighting, electric lighting and glare), building energy, life-cycle assessment, acoustic.

With the available of weather data, solar study can be conducted to analyze indoor thermal comfort. Most of the BIM-based simulation tools employ weather data files from Energy Plus or the US Department of Energy. Shadow casting analysis, solar radiation and heat gain can be simulated to investigate the indoor thermal performances of a building. By understanding the solar radiation distribution, proper fenestration and shading device design can be proposed. Besides, the appropriate location of photovoltaic panel for solar energy can be determined to optimize the performance (Lim et al., 2013a).

Daylighting simulation is important to study the potential use of daylight as renewable energy resource to reduce the reliance on electric lighting. Most of the available BIM-based daylighting simulation tools use Radiance simulation engine (Lim et al., 2013b; Lim, 2014). Radiance employs CIE sky standard skies for simulation, which include Clear Sky, Intermediate Sky with Sun, Intermediate Sky without Sun, Overcast Sky and Uniform Sky. Various daylighting performances can be analyzed such as illuminance level (lux), daylight factor (DF, \%), luminance $\left(\mathrm{cd} / \mathrm{m}^{2}\right)$ and glare index. Some tools such as IES $<\mathrm{VE}>$ integrate electric lighting performance with daylighting in order to study the potential energy saving by using photo sensors.

Another important feature in BIM-based simulation is Computational Fluid Dynamic (CFD) to study the ventilation and wind flow. CFD is useful not only to analyze the indoor wind flow pattern, but also to simulate the wind velocity and air change rate. Apart from that, wind flow will also affect users' thermal comfort. 


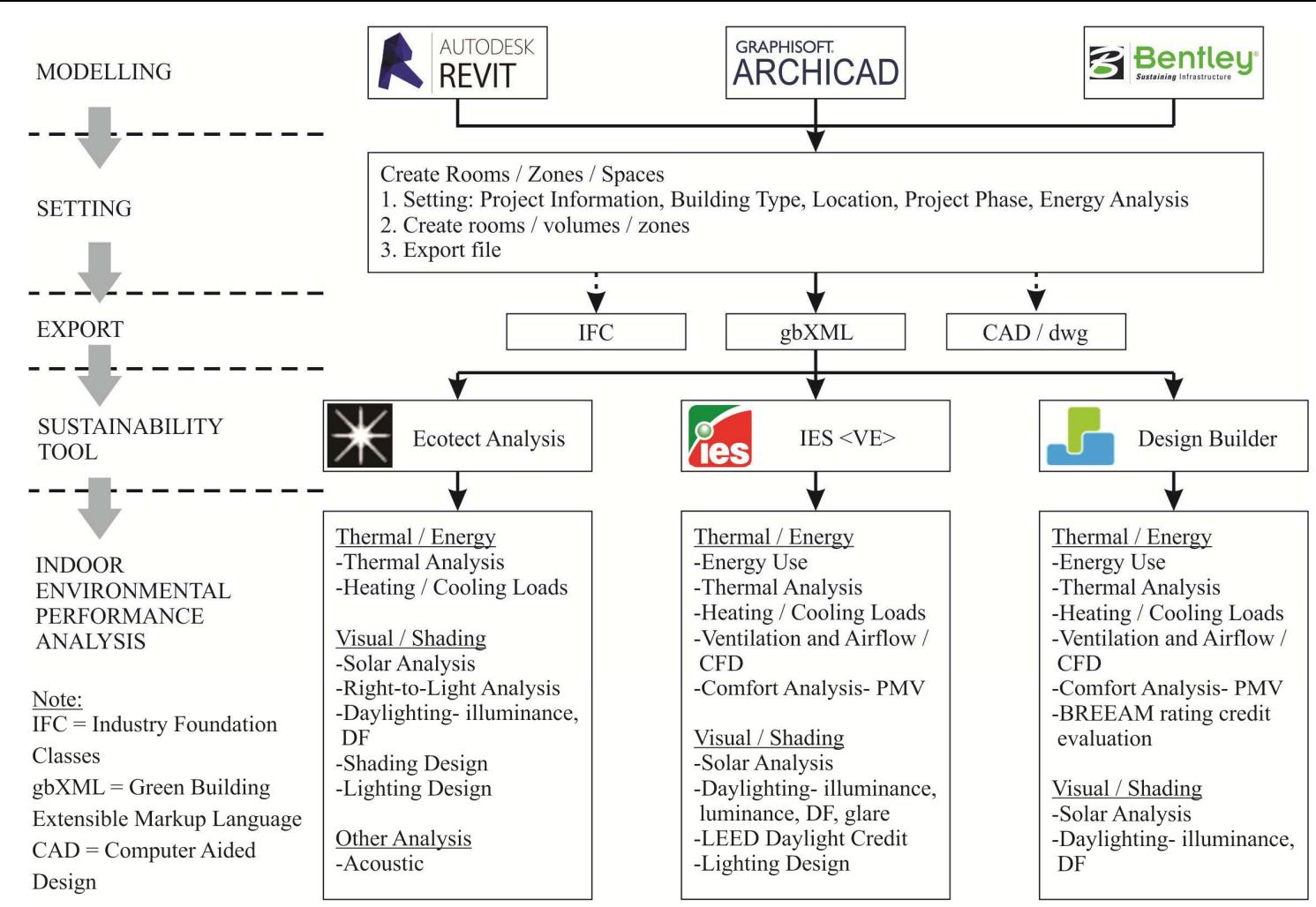

Fig. 1. Application of BIM-based sustainability tools for indoor environmental performance analysis

Hence, CFD is useful to simulate Predicted Mean Vote (PMV) for indoor thermal comfort analysis. However, most of the BIM-based simulation tools have constraints in CFD simulation such as the limited complexity of the model and inability to accurately simulate odd or curved building form.

Total building energy performance can also be evaluated using BIM-based simulation by considering heating or cooling load, electric lighting load, occupancy loads. Proper definitions of HVAC system and types of electric lighting are important to assure the accuracy of the outputs. The solar shading, daylighting and ventilation performances are also integrated for the building energy use simulation. Furthermore, many of the simulation tools also provide evaluation based on certain ratings such as LEED and BREEAM.

\section{Prospect}

In the conventional AEC workflow, indoor building performance analysis is mostly done subsequent to the architects' design by the experts such as engineers. The information or data from the drawings produced by the architects will be translated into digital model for simulation. The experts will use simulation software to evaluate specific or overall building performances based on the architects' designs. Thus, simulation is used as final evaluation tools rather than design tools to help developing the building design. This has hampered evidence-based design method. Therefore, the development of BIM-based simulation is very crucial to allow building performance studies begin in the early stages of designs (Schlueter and Thesseling, 2009; Brahme et al., 2001).

\section{Recent AEC Industry Market Trend}

Although many benefits of using BIM have been highlighted by previous studies, concurrently there are a lot of challenges in implementing it. BIM adoption is much slower than anticipated due to two main reasons: Technical and managerial (Gu and London, 2010; Fischer and Kunz, 2004). The technical reasons are classified into 3 categories (Bernstein and Pittman, 2005):

- The need for well-defined transactional construction process models to eliminate data interoperability issues

- The requirements that digital design data be computable

- The need for well-developed practical strategies for the purposeful exchange and integration of meaningful information among the BIM model components

For the management issues, the challenges appeared in the implementation and use of BIM. Until now, there is no single document on BIM that instructs on its application or usage (Azhar et al., 2008; AGCA, 2005). Hence, there is an urgent demand to standardize the $\mathrm{BIM}$ process and to define the guidelines for 
implementation of BIM. Another issue among the AEC industry stakeholders (i.e., owners, designers and constructors) is the unclear role or responsibility to develop and operate BIM models as well as the distribution of developmental and operational costs.

Although implementing BIM faces various challenges, recent market surveys in year 2012 evidenced that $70 \%$ of the architectural offices in the US already adopted BIM in their practices especially for large size firms. Furthermore, 39\% of them were very heavy users (McGHC, 2012). However, the percentages of architectural offices using BIM are comparatively low in other regions such as Southeast Asia. In order to convince the practitioners to implement BIM-based design and simulation, marketing of BIM need to be supported by a rigorous cost/benefit analysis (Bryde et al., 2013).

McGHC (2008) had conducted a survey on about 300 BIM practitioners to identify the most often used BIM analyses. The results showed that $38 \%$ of them used BIM for energy analysis while $35 \%$ of them employed BIM for LEED/green analysis. On the other hand, a survey by Azhar and Brown (2009) demonstrated that the most common sustainability analyses were found to be energy analysis (83\%), daylighting/solar analysis (60\%), building orientation analysis (53\%), massing analysis (47\%) and site analysis (37\%). These findings evidenced high percentages of BIM-based sustainability analyses implementations among the BIM practitioners. According to a study by McGHC (2012), airflow or CFD analysis was to least used by architects and engineers.

\section{Recent Research Trend}

Recent research on BIM-based sustainability looked into the potential of extracting the data directly from a BIM model for green rating assessment. For instance, Azhar et al. (2011) studied the relationship between BIM-based sustainability analyses types and LEED credits in US. The finding concluded that documentation for LEED credits may be directly or indirectly prepared using the results of BIM-based sustainability analyses software. Third-party tool such as IES $<$ VE $>$ is needed to obtain the documentation for LEED credits. Nevertheless, the disadvantage of exporting BIM-based model to third-party sustainability simulation tools is that these tools do not make the BIM model dynamic. After getting the results from the simulations, any modification to optimize the performance cannot be translated automatically back into the BIM model (Bank et al., 2010).

Kim et al. (2013) aimed to develop Green BIM Template (GBT) for Green Building Certification Criteria (GBCC) in South Korea. It included GBT Input as a guide platform for environmental analysis modeling and GBT Output as a platform connected to GBCC. Through GBT, data from a BIM model can be extracted for rapid response to $\mathrm{GBCC}$ requirements. As one of the challenges to implement BIM is lack of welldefined transactional process, research was conducted to develop prototype workflow to apply BIM-based environmental analysis according to various project stages (Ko et al., 2013).

The current methods for designing green buildings rely on a number of disjointed analyses to determine whether discrete requirements have been met by various building systems or design features. Therefore, Bank et al. (2010) investigated the possibility to develop a decision-making framework for sustainable building design and operation by integrating BIM with System Dynamics. This framework addresses the difficulties of making decisions in the earlier design process and allows for specific sustainability trade-off analyses to be conducted. From the recent development on BIM-based sustainability analyses, it can be anticipated that more research will be conducted on extracting data directly from BIM model for sustainability design process and rating assessment without employing third-party simulation tool.

\section{Conclusion}

This study presents the application of BIM-based simulation tools to realize sustainable building throughout various architectural design stages. Some well-known BIM-based simulation tools are discussed and compared. BIM allows extraction of building information directly from a single modeling as developed by the architect for various building performances analyses such as solar study, daylighting, building energy use, CFD. This provides simultaneous process between architectural design development and building indoor environmental performance studies in order to achieve sustainability in a more time and cost effective workflow. This is very essential because simulation during early or pre-design stage is very crucial to test and improve the building performances. Subsequently, more efforts in promoting BIM-based design and simulation methods in AEC industry are necessary to achieve sustainable built environment.

The review shows that one of the critical challenges in implementing BIM-based sustainability analyses is the lack of well-defined transactional process models and practical strategies for integration of information. Hence, many researchers had made effort to study the BIM-based analysis workflow according to various design development stages. Nevertheless, till today there is no standard guideline for BIM-based modeling especially for indoor environmental performances evaluation. This hinders 
the adoption of BIM-based sustainability analyses in AEC industry. More efforts are required to further develop framework and guidelines for BIM-based design and analysis process to achieve comfortable indoor environment and sustainable development.

\section{Acknowledgement}

The author would like to acknowledge the research funding by Ministry of Education Malaysia (MOE) through Fundamental Research Grant Scheme (FRGS) Vote 4F665, titled "BIM-GBI Model Development: Integrating Building Information Modelling and Green Building Certification in Malaysia”.

\section{Ethics}

This article is original and contains unpublished material. The corresponding author confirms that all of the other authors have read and approved the manuscript and no ethical issues involved.

\section{References}

AGCA, 2005. The Contractor's Guide to BIM. 1st Edn., AGC Research Foundation, Las Vegas, NV.

Azhar, S. and J. Brown, 2009. BIM for sustainability analyses. Int. J. Construct. Educ. Res., 5: 276-292. DOI: 10.1080/15578770903355657

Azhar, S., W.A. Carlton, D. Olsen and I. Ahmad, 2011. Building information modeling for sustainable design and LEED $®$ rating analysis. Automat. Construct., 20: 217-224. DOI: 10.1016/j.autcon.2010.09.019

Azhar, S., A. Nadeem, J.Y.N. Mok and B.H.Y. Leung, 2008. Building Information Modeling (BIM): A new paradigm for visual interactive modeling and simulation for construction projects. Proceedings of the 1st International Conference on Construction in Developing Countries, Aug. 4-5, Karachi, Pakistan, pp: 435-446.

Bank, L.C., M. McCarthy, B.P. Thompson and C.C. Menassa, 2010. Integrating BIM with system dynamics as a decision-making framework for sustainable building design and operation. Proceedings of the 1st International Conference on Sustainable Urbanization, Dec. 15-17, Hong Kong, China, pp: 1-9.

Barlish, K. and K. Sullivan, 2012. How to measure the benefits of BIM-a case study approach. Automat. Construct., 24: 149-159.

DOI: $10.1016 /$ j.autcon.2012.02.008

Bernstein, P.G. and J.H. Pittman, 2005. Barriers to the Adoption of Building Information Modeling in the Building Industry. 1st Edn., Autodesk Building Solutions Whitepaper, Autodesk Inc., CA.
Brahme, R., A. Mahdavi, K. Lam and S. Gupta, 2001. Complex Building Performance Analysis in Early Stages of Design, 1st Edn., IBPSA, Rio de Janeiro, Brazil.

Bryde, D., M. Broquetas and J.M. Volm, 2013. The project benefits of Building Information Modelling (BIM). Int. J. Project Manage., 31: 971-980. DOI: 10.1016/j.ijproman.2012.12.001

Crawley, D.B., L.K. Lawrie, F.C. Winkelmann, W.F. Buhl and Y.J. Huang et al., 2001. EnergyPlus: Creating a new-generation building energy simulation program. Energy Build., 33: 319-331. DOI: $10.1016 / \mathrm{S} 0378-7788(00) 00114-6$

Fischer, M. and J. Kunz, 2004. The scope and role of information technology in construction. Proceedings of JSCE 763, (JSCE' 04), Stanford University, pp: 1-8.

$\mathrm{Gu}, \mathrm{N}$. and K. London, 2010. Understanding and facilitating BIM adoption in the AEC industry. Automat. Construct., 19: 988-999.

DOI: $10.1016 /$ j.autcon.2010.09.002

Ibarra, D.I. and C.F. Reinhart, 2009. Daylight factor simulations-how close do simulation beginners 'Really' Get? Proceedings of the 11th International IBPSA Conference, Jul. 27-30, Glasgow, Scotland. pp: $1-8$.

Kim, I., M. Kim and H. Jun, 2013. GBT for BIMbased green building certification system. Proceedings of the International Conference on Sustainable Building Asia, Jul. 8-10, Seoul, South Korea, pp: 193-197.

Ko, J., Y.P. Kim, G.R. Kim, S. Kim and S.H. Ann, 2013. The study of BIM-based energy and environmental performance analysis process for sustainable remodelling. Proceedings of the International Conference on Sustainable Building Asia, Jul. 8-10, Seoul, South Korea, pp: 444-448.

Lim, Y.W., 2012. Building Modelling and Simulation for Green Building Design. In: Sustainability in Built Environment I, Bahru, J. (Ed.), Institute Sultan Iskandar, Universiti Teknologi Malaysia.

Lim, Y.W., 2014. Dynamic daylight and solar control in tropical climate. Am. J. Applied Sci., 11: 17661772. DOI: 10.3844/ajassp. 2014.1766.1772

Lim, Y.W., D.R. Ossen and Y.W. Lim, 2008. Review on measuring tools for energy efficient solar shading strategies in tropical climate. J. Alam. Bina, 14: 33-42.

Lim, Y.W., A. Mohd Hamdan and D.R. Ossen, 2010. Empirical validation of daylight simulation tool with physical model measurement. Am. J. Applied Sci., 7: 1412-1419. DOI: 10.3844/ajassp.2010.1426.1431 
Lim, Y.W., A. Mohd Hamdan and A. Syed Iskandar, 2013a. University-industry research collaboration on development of green mosque design. Proceedings of 1st Asia Future Conference, Mar. 8-10, Centara Grand at Central Plaza Ladprao Bangkok, Thailand.

Lim, Y.W., A. Mohd Hamdan and D.R. Ossen, 2013b. Internal shading for efficient tropical daylighting in existing high-rise open plan office. Indoor Built Environ., 22: 932-951. DOI: $10.1177 / 1420326 X 12463024$

Lim, Y.W., K. Mohd Zin, A. Mohd Hamdan, D.R. Ossen and M.A. Aminatuzuhariah, 2012. Building façade design for daylighting quality in typical government office building. Build. Environ., 57: 194-204. DOI: 10.1016/j.buildenv. 2012.04.015

Loutzenhiser, P.G., G.M. Maxwell and H. Manz, 2007. An empirical validation of the daylighting algorithms and associated interactions in building energy simulation programs using various shading devices and windows. Energy, 32: 1855-1870. DOI: 10.1016/j.energy.2007.02.005

McGHC, 2012. The Business Value of BIM. in North America-Multi-Year Trend Analysis and User Ratings (2007-2012). 1st Edn., McGraw Hill Construction, Bedford, Massachusetts.

McGHC, 2010. Smart-Market Report. 1st Edn., McGraw Hill Construction, Bedford, Massachusetts.
McGHC, 2008. Building Information Modeling Trends Smart Market Report. 1st Edn., McGraw Hill Construction, New York.

Pedrini, A. and R. Hyde, 2001. A database energy tool for design-phase assessment of office buildings. Proceedings of the 18th Conference on Passive and Low Energy Architecture, Nov. 7-9, Florianópolis, Brazil, pp: 1-8.

Reinhart, C. and A. Fitz, 2006. Findings from a survey on the current use of daylight simulations in building design. Energy Build., 38: 824-835. DOI: 10.1016/j.enbuild.2006.03.012

Sanguinrtti, P., S. Abdelmohsen, J. Le, J. Lee and H. Sheward et al., 2012. General system architecture for BIM: An integrated approach for design and analysis. Adv. Eng. Inform.. 26: 317-333. DOI: $10.1016 /$ j.aei.2011.12.001

Schlueter, A. and F. Thesseling, 2009. Building information model based energy/exergy performance assessment in early design stages. Automat. Construct., 18: 153-163. DOI: $10.1016 /$ j.autcon.2008.07.003

Woo, J., J. Wilsmann and D. Kang, 2010. Use of as-built building information modeling. Construct. Res. Cong., 1: 538-547. DOI: 10.1061/41109(373)54

Xia, C., Y. Zhu and B. Lin, 2008. Building simulation as assistance in the conceptual design. Build. Simulat., 1: 46-52. DOI: 10.1007/s12273-008-8107-y 